\title{
Representações Sociais do “Ser Indígena”: Uma Análise a Partir do Não Indígena
}

\author{
Sílvia Barbosa Correia \\ ${ }^{1}$ Universidade de Fortaleza, Fortaleza, CE, Brasil.
}

\author{
Luciana Maria Maia ${ }^{1}$ \\ ${ }^{1}$ Universidade de Fortaleza, CE, Brasil.
}

Resumo: O presente estudo trata-se de uma pesquisa de natureza qualitativa descritiva que teve como objetivo conhecer as representações sociais do "ser indígena", considerando as imagens e significados compartilhados por não indígenas. Como fundamentação, utilizou-se a Teoria das Representações Sociais e referências da antropologia. Em relação ao método, participaram 38 pessoas não indígenas da cidade de Fortaleza, abordadas em locais públicos ou de convivência, que responderam aos seguintes instrumentos: Teste de Associação Livre de Palavras (TALP), entrevista semiestruturada e questionário sociodemográfico. Para análise das informações coletadas, foram tabelados os dados sociodemográficos e foi realizada uma análise do TALP, considerando a frequência dos termos evocados e a organização do conteúdo em cinco categorias temáticas: sujeito distinto, sujeito primitivo, sujeito de direito, sujeito excluído e sujeito valorizado. Para a análise do corpo textual das entrevistas, utilizou-se o software ATLASTI, que permitiu, a partir da análise de trechos das entrevistas, a visualização de categorias, a criação de códigos e a elaboração de uma rede semântica, que auxiliou a interpretação dos resultados. As representações acerca do indígena estão ancoradas em um conhecimento prévio que lhe atribui uma condição de sujeito primitivo. A população não indígena, alienada em sua própria cultura, sem contato e experiências com indígenas, reproduz uma violência simbólica e cultural contra esses grupos étnicos. O conhecimento desmistifica os estereótipos e faz com que o indígena possa ser respeitado em sua cultura e, ao mesmo tempo, reconhecido como sujeito de direitos, como qualquer outro cidadão.

Palavras-chave: Representações Sociais, Indígena, Não indígena.

\section{Social Representations of "Being Indigenous": an Analysis from the Non-indigenous}

\begin{abstract}
This is a qualitative descriptive research that aimed to understand the social representations of "being indigenous" from images and meanings shared by non-indigenous people based on the Theory of Social Representations and anthropological references . To this end, the Word-Association Test (WAT), semi-structured interviews, and a sociodemographic questionnaire were applied to 38 non-indigenous people from the city of Fortaleza approached in either public or social settings. Sociodemographic data were tabulated and information collected by the WAT were analyzed considering the frequency of the terms evoked, organized into five thematic categories: distinct subject, primitive subject, subject of law, excluded subject, and valued subject. The ATLAS.ti software was used to analyze excerpts from the interviews, enabling the visualization of categories, the creation of codes, and the development of a semantic network that favored results interpretation. Results indicate that social representations about indigenous people are anchored in a dated knowledge that places these people as primitives. Alienated in their own culture, without contact and experiences with indigenous people, the nonindigenous population reproduces symbolic and cultural violence against these ethnic groups. In this scenario, knowledge functions as to demystify stereotypes, promoting respect towards the indigenous culture while recognizing them as a subject of rights, just like any other citizen.
\end{abstract}

Keywords: Social representations, Indigenous, Non-Indigenous. 


\title{
Representaciones Sociales de "Ser Indígena”: un Análisis de los no Indígenas
}

\begin{abstract}
Resumen: Este estudio cualitativo descriptivo tuvo como objetivo comprender las representaciones sociales de "ser indígena" considerando las imágenes y significados compartidos por personas no indígenas. Como base teórica se utilizaron la teoría de las representaciones sociales y las referencias de la antropología. En cuanto al método, participaron 38 personas no indígenas de la ciudad de Fortaleza (Brasil), abordadas en lugares públicos o de convivencia, que respondieron a los siguientes instrumentos: Test de Asociación Libre de Palabras (TALP), entrevista semiestructurada y cuestionario sociodemográfico. Para el análisis de los datos se tabuló los datos sociodemográficos y se realizó un análisis delTALP, considerando la frecuencia de los términos evocados y la organización en cinco categorías temáticas: sujeto distinto, sujeto primitivo, sujeto de derecho, sujeto excluido y, por el fin, sujeto valorizado. Para el análisis del cuerpo textual de las entrevistas, se utilizó el software ATLAS.ti, que posibilitó, a partir del análisis de extractos de las entrevistas, la visualización de categorías, la creación de códigos y el surgimiento de una red semántica que favorece la interpretación de los resultados. Las representaciones acerca del indígena están ancladas en conocimiento previo que lo coloca en una condición de sujeto primitivo. La población no indígena, alienada en su propia cultura, sin contacto y experiencias con los pueblos indígenas, reproduce una violencia simbólica y cultural contra estos grupos. El conocimiento desmitifica los estereotipos al hacer que el indígena sea respetado en su cultura y, al mismo tiempo, reconocido como sujeto de derechos como cualquier otro ciudadano.
\end{abstract}

Palabras clave: Representaciones Sociales, Indígena, No indígena.

\section{Introdução}

A identidade étnica dos povos indígenas do Brasil é constantemente questionada pela sociedade não indígena. Isso se deve à representação do indígena, que o vincula a uma figura do passado, um selvagem que vivia em terras brasileiras à época do descobrimento e da colonização (Braga \& Campos, 2012; Lima, Faro, \& Santos, 2016). Ao longo dos anos em contato com o "homem branco" colonizador, os indígenas viveram um processo de extermínio da quase totalidade de suas populações, ora por epidemias, ora por guerras - ou, ainda, por negação de sua existência por parte da sociedade brasileira (Souza \& Barbosa, 2011).

Especificamente no Nordeste, os povos indígenas sofreram muita discriminação, eram pobres e sertanejos, não tinham acesso à terra e eram desprovidos de forte contrastividade cultural. Interesses econômicos e sociais, assim como a necessidade de dominação e expansão de territórios, justificaram as atitudes dos colonizadores diante dos povos indígenas e dos negros oriundos da África. A visão dos povos indígenas como selvagens contribuiu para a relação de desigualdade e dependência a que tais grupos foram submetidos pelos colonizadores e, em seguida, pela sociedade "branca", que lhe atribuiu ao longo da história uma condição de inferioridade. Assim, a imagem construída - de que eram povos inferiores, atrasados e desprovidos de cultura, justamente por associá-los a animais selvagens -se estabeleceu no imaginário do povo brasileiro ao longo da história (Oliveira, 1998).

O processo de colonização - o contato entre povos indígenas e colonizadores no decorrer da história do Brasil - modificou o modo de vida e muitas das características dos grupos étnicos espalhados por todo o território. As consequências desse processo de aculturação e das relações de poder econômico e social entre sociedade não indígena, Estado e indígenas brasileiros, fortaleceram o processo de exclusão desses grupos étnicos (Luciano, 2006).

Alguns marcos históricos legais indicam que essa relação entre indígenas e não indígenas sempre se caracterizou pela subjugação. Os povos indígenas no Brasil passaram de selvagens para tutelados, segundo a Constituição Federal Brasileira de 1924, até atingirem a condição de sujeitos de direitos com a última Constituição nacional. Este último processo 
se deu a partir da reivindicação de grupos étnicos pelo reconhecimento de sua identidade e de seus direitos (Pinheiro, 2002).

No final da década de 1970, um projeto de emancipação previa discriminar, entre os indígenas, aqueles que preservavam características culturais atribuídas a seus grupos étnicos, diferenciando-os de outros que eram considerados não indígenas por não preservarem tais características. Esse projeto pretendia limitar a responsabilidade do Estado quanto àqueles reconhecidos como indígenas, considerando as características da "indianidade" (Castro, 2006).

Contrapondo-se a esse projeto, um movimento político do campo da antropologia defende que o indígena não pode ser definido por seus trajes e aparência, mas por seu modo de vida, suas crenças e reconhecimento de sua identidade étnica (Leite, 1979). Nessa direção, também merece destaque a intervenção política dos povos indígenas na Assembleia Constituinte de 1987, por meio da fala de Ailton Krenak, que denunciou a violência e a negligência dirigidas aos povos indígenas e reivindicou a inclusão desses povos na nova Constituição, contemplando-os com direitos fundamentais como a demarcação de seus territórios e o reconhecimento de suas culturas e tradições. Essas reivindicações foram atendidas na Constituição de 1988; contudo, até os dias de hoje, a violação desses direitos e práticas genocidas ameaçam a existência desses grupos étnicos (Jaenisch, 2017).

Nessa perspectiva, o ser indígena implica a junção de elementos de sua história passada, do momento atual, de lutas políticas e processos de resistência e das perspectivas futuras, referentes ao respeito à diversidade cultural, à garantia de seus territórios e ao reconhecimento dos indígenas como sujeitos de direitos. A afirmação dessa identidade étnica ocorre a partir do fortalecimento dos laços grupais e das práticas culturais, na intenção de preservar e recuperar aspectos da cultura que marcam a distintividade étnica. Esse processo se caracteriza enquanto resistência dos povos indígenas frente à ideia de sua integração à sociedade dominante (Braga, 2005).

Essa resistência, na perspectiva de Bourdieu (1989), configura-se enquanto luta coletiva pela subversão e consequente transformação das relações simbólicas de poder, de modo a criar uma condição de autonomia favorável à apropriação de uma identidade legítima, não sujeita à atribuição de critérios negativos. Para o autor, trata-se de um processo simbólico de reapropriação coletiva sobre o que rege a construção e a avaliação da identidade grupal. Nas palavras de Bourdieu (1989),

... indivíduos e grupos investem nas lutas de classificação todo o seu ser social, tudo o que define a ideia que eles têm deles próprios, todo o impensado pelo qual eles se constituem como "nós" por oposição a "eles", aos "outros" e ao qual estão ligados por uma adesão quase corporal. É isto que explica a força mobilizadora excepcional de tudo o que toca à identidade (p. 124).

Nessas relações intergrupais, Munduruku (2010) afirma que populações indígenas sofrem as consequências de viver em contato permanente com uma sociedade que as marginaliza e nega sua identidade cultural. Para esse autor, "se por um lado manter-se indígena é condição fundamental para o reconhecimento étnico, ... a aprender a conviver com a sociedade em igual condição é considerado um abandono de identidade" (Munduruku, 2010, p. 67). Nessa perspectiva, prevalece a crença de que indígenas que adotam hábitos e comportamentos do não índio têm sua identidade étnica comprometida, o que ocorre principalmente com indígenas que estão fora do convívio de sua comunidade étnica, os chamados "desaldeados". O território e a cultura são elementos que garantem a existência dos povos indígenas. A preservação da cultura e sua manifestação na sociedade assumem o caráter de resistência na luta contra os preconceitos, ao mesmo tempo em que dão visibilidade e demandam respeito e reconhecimento ao valor histórico dos indígenas e de seus direitos enquanto membros de uma nação (Munduruku, 2010; Potiguara, 2018).

No Brasil, apesar dos direitos constitucionalmente garantidos à população indígena, o que se tem constatado na prática é um conjunto de ações desestruturadoras que favorecem a violação de direitos dos povos indígenas. Dados do último relatório anual do Conselho Indigenista Missionário (CIMI, 2019) apontam diversas situações de violação de direitos individuais e coletivos, como invasão de territórios, exploração de terras indígenas por garimpos, processos demarcatórios paralisados, discursos discriminatórios e, ainda, desrespeito à política indigenista, que já previa ações no âmbito da saúde e da educação, conquistas históricas que atualmente estão precarizadas. Essas formas de violação ameaçam, de alguma forma, a existência dos povos indígenas (CIMI, 2019). 
A violação desses direitos ocorre na contramão da Declaração das Nações Unidas sobre os Direitos dos Povos Indígenas (ONU, 2007), da qual o Brasil é signatário. Esse documento reflete um conjunto de reivindicações atuais dessa população acerca de melhorias nas relações com os estados nacionais, visando ao reconhecimento e ao respeito à diferença étnico-cultural como condições imprescindíveis à existência e garantia de vida digna das populações indígenas.

A luta indígena no Ceará tem algumas especificidades. Os indígenas foram considerados povos inexistentes em 1863 e somente na década de 1980 retomaram seu processo de afirmação identitária processo chamado por antropólogos de "etnogênese" (Oliveira, 1998). Desse modo, hoje muitas etnias indígenas ainda vivem um processo de ressurgimento diante da sociedade não indígena, o que implica na afirmação de suas identidades étnicas e no resgate de culturas ancestrais. Na década de 1980, a Fundação Nacional do Índio (FUNAI) reconheceu a existência do povo Tapeba, que, apoiado pela Igreja Católica, procurou aquele órgão, demandando a regularização de suas terras. O povo Tapeba foi seguido por outros povos indígenas do Ceará e, atualmente, o estado conta com 14 etnias reconhecidas - Tapeba, Tabajara, Potyguara, Pitaguary, Tremembé, Anacé, Kanindé, Tapuia-Kariri, Jenipapo-Kanindé, Kalabaça, Tapuia, Kariri, Gavião e Tupinambá -, que se distribuem em 19 municípios, totalizando cerca de 28.900 indivíduos (Associação para o Desenvolvimento Local Co-Produzido [ADELCO], 2017).

Considerando os aspectos apresentados, é possível discutir que o ser indígena abrange diversos elementos, entre fatores históricos, políticos e culturais, bem como implica reconhecer experiências de preconceito e discriminação vividas por esses povos. A Teoria das Representações Sociais (TRS) orienta este estudo por possibilitar a articulação de saberes de distintas disciplinas, com o propósito de vislumbrar análises mais amplas, que contemplem diferentes níveis (Doise, 2002; Moscovici, 2015; Valentim, 2013). Além disso, a escolha pela TRS se deve ao fato de que os estudos pautados nessa teoria reconhecem a necessidade de se compreender os significados e tensionamentos em jogo, para promover a mudança da realidade social (Valentim, 2013).

A TRS possibilita o estudo das relações entre fenômenos sociais e cognitivos a partir da comunicação e do pensamento. As representações sociais são indispensáveis para se compreender a dinâmica das interações e das práticas decorrentes dessas relações (Chaves \& Silva, 2013). Do ponto de vista epistemológico, existem diferentes abordagens para análise das representações sociais. Neste trabalho, utiliza-se primordialmente a abordagem sociogenética, relacionada aos trabalhos de Moscovici e Jodelet, que estuda o fenômeno das representações sociais na perspectiva das condições e dos processos envolvidos na emergência dessas representações, como foco nos processos de ancoragem e objetivação (Moliner \& Guimelli, 2015).

A objetivação é um processo por meio do qual grupos sociais constroem um conhecimento comum baseado em trocas e opiniões compartilhadas. Esse processo descreve a forma como uma representação se torna real, isto é, como é materializada e naturalizada nas relações sociais (Moscovici, 2015). Por sua vez, a ancoragem é o processo pelo qual algo estranho, não familiar, é classificado numa categoria já existente. Ela envolve a integração de algo novo a um sistema de informações ou a esquemas de pensamento que servem como pontos de referência para a nova representação (Vala \& Castro, 2013). A ancoragem ocorre pela necessidade das pessoas de dar significados, classificar, rotular e nomear algo desconhecido, tornando-o familiar (Moscovici, 2015). Esses processos permitem explicar como uma representação social é construída em relação aos valores, crenças e conhecimentos disponíveis ao grupo social (Moscovici, 2015). No campo das relações intergrupais, por meio dos processos de categorização e comparação entre grupos, indivíduos tentam manter ou reforçar sua autoestima positiva em relação ao grupo de pertencimento, o que favorece o fortalecimento da identidade social (Deschamps \& Moliner, 2009; Tajfel, 1982).

Pode-se afirmar, então, que as representações sociais contribuem para o processo de diferenciação social na medida em que as especificidades dos grupos sociais geram representações próprias que podem favorecer o preconceito e a discriminação social em relação aos membros desses grupos (Vala \& Castro, 2013). O preconceito pode ser descrito como atitude aversiva ou hostil, sentida ou expressa, dirigida a um grupo ou a uma pessoa por ela ser reconhecida como membro de um grupo específico (Allport, 1954). Nessa perspectiva, compreende-se o preconceito como algo relacionado às representações sociais compartilhadas sobre um grupo (Lima, 2013). 
Estudos no campo da Psicologia Social apontam que as representações acerca do indígena são marcadas por estigmas que os colocam em uma condição desfavorável frente à sociedade em geral. Preguiçoso, selvagem, atrasado e oportunista são algumas representações a respeito do indígena, que o desqualificam e desumanizam ( Lima, \& Almeida, 2010; Lima et al., 2016). A falta de conhecimento e de proximidade com esses grupos, bem como a influência da mídia que reforça os estereótipos e os interesses econômicos contrários ao modo de vida dessas populações, são algumas formas de justificar as representações sociais que se formam em torno do índio brasileiro (Braga \& Campos, 2012; Lima, \& Almeida, 2010; Lima et al., 2016; Stock \& Fonseca, 2013).

Os resultados de um estudo que investigou a imagem dos indígenas entre não indígenas moradores de Sergipe e de Alagoas, apontam que a representação acerca do indígena reúne atributos como "selvagem", "exótico" e "invisível", bem como atributos que os desqualificam e os desvalorizam moralmente, tais como "aproveitadores", "preguiçosos" e "violentos" (Lima et al., 2016). Outro estudo, desenvolvido no contexto da demarcação e desocupação de reservas indígenas em Roraima, demonstrou a influência da mídia na construção de uma realidade particular que coloca o indígena numa condição de invisibilidade e subalternidade frente ao poder econômico e estatal, segundo o qual a ideia de tutela e a imagem do indígena são associadas à violência (Braga \& Campos, 2012). Resultados de outro estudo, que abordou a relação entre indígenas e não indígenas no âmbito da chegada de povos indígenas à cidade de Porto Alegre (RS) sugerem que a presença de indígenas na área urbana incomoda a população não indígena e promove discursos que remetem à representação do indígena como ser da floresta cuja identidade étnica só é legítima se lá permanecer (Stock \& Fonseca, 2013).

Um estudo sobre as representações do corpo indígena compartilhadas no Twitter, desenvolvido na ocasião do evento Acampamento Terra Livre, realizado em abril de 2017, aponta para uma identidade genérica e estereotipada do indígena (corpo seminu, pinturas corporais, arco, flecha, cocar), que se construiu a partir da historiografia oficial. Tal representação legitima estratégias de visibilidade das demandas sociais e políticas dos grupos indígenas frente ao Estado e à sociedade brasileira, enquanto imagens que não se aproximam desses estereótipos colocam à prova o pertencimento étnico dos indígenas. Logo, o estudo aponta que uma suposta perda cultural ameaça o pertencimento étnico sob o olhar dos não indígenas (Bonin, Kirchof, \& Ripoll, 2018).

Alguns estudos exploram a percepção da discriminação individual e grupal contra indígenas. Nesse sentido, um estudo exploratório e descritivo, com indígenas da reserva de Quitirrisí, na Costa Rica, indicou altos níveis de percepção de discriminação contra o grupo étnico, confirmando o reconhecimento da discriminação sofrida por grupos minoritários, que se utilizam de uma identidade social positiva como forma de proteção das desigualdades (Salas, 2011). Em Bangladesh, um estudo feito com a comunidade indígena Chakma e com colonos que vivem no sudeste do país, os bengalis, examinou pensamentos e percepções estereotipados. Os resultados indicaram ideias sobre o indígena com alto nível de preconceito e, diante de tal resultado, os pesquisadores propõem rever as estratégias de redução do preconceito a partir do aumento do contato entre os grupos (Mozumder \& Haque, 2015).

Considerando os pressupostos teóricos apresentados, o contexto descrito e os achados assinalados, propõe-se uma pesquisa que tem como objetivo conhecer as representações sociais do "ser indígena", considerando as imagens e os significados compartilhados por não indígenas.

\section{Método}

\section{Amostra}

Participaram deste estudo 38 pessoas que se reconheciam como "não indígenas", residentes na cidade Fortaleza e na região metropolitana, com idades entre 18 e 50 anos $(\mathrm{X}=27,5 ; D P=9,1)$, a maioria do sexo feminino ( $\mathrm{N}=27 ; 71 \%)$, solteiras $(\mathrm{N}=29 ; 76,3 \%)$, com ensino superior incompleto ( $\mathrm{N}=16 ; 42,1 \%)$, de religião católica $(\mathrm{N}=15 ; 39,5 \%)$, que se autodeclararam pardas $(\mathrm{N}=22$; $57,9 \%)$ e com renda em torno de três salários mínimos.

A amostra foi não aleatória e intencional, por ter sido priorizada a facilidade de acesso da pesquisadora aos participantes e a disponibilidade deles para participar da pesquisa. Para a composição dessa amostra, foi abordado três vezes o número de pessoas para alcançar tal quantidade de participantes, considerada adequada segundo os critérios de saturação dos dados (Minayo, 2017). 


\section{Instrumentos}

Para caracterizar os participantes quanto ao perfil sociodemográfico, utilizou-se um questionário objetivo, com perguntas sobre idade, gênero, local de moradia, estado civil, nível de escolaridade, religião, renda mensal e percepção de cor/etnia.

Considerando que os indígenas fazem parte de um grupo social pouco visibilizado na sociedade (ADELCO, 2017; Oliveira, 1998), utilizou-se o Teste de Associação de Livre de Palavras (TALP), com o estímulo indutor "índio". O TALP é uma técnica de fácil compreensão, administração e adaptação aos interesses de um determinado estudo (Palacios-Espinosa, González, \& Zani, 2015). Desse modo, o uso preliminar do TALP teve como propósito facilitar o envolvimento dos participantes na entrevista.

Para a entrevista, foi utilizado um roteiro semiestruturado, composto por 10 perguntas sobre concepções acerca dos indígenas, conhecimentos, formas de acesso a essas informações, contato e experiências prévias com indígenas. A entrevista foi utilizada como instrumento principal e o TALP, como instrumento complementar. Ambas as técnicas têm sido utilizadas em estudos qualitativos (Fernandes, Ferraz, Salvaro, Castro, \& Soratto, 2018).

\section{Procedimentos de coleta e análise dos dados}

A realização da pesquisa aconteceu em abril de 2018, mês em que se discute questões relativas à problemática indígena no país, por se considerar ser este um período de mais visibilidade desse grupo étnico. Os participantes foram contactados em locais públicos e de convivência da cidade de Fortaleza, e, após receberem as informações sobre o objetivo da pesquisa, foram feitos o convite e a leitura do Termo de Consentimento Livre e Esclarecido (TCLE), que continha as condições sobre a participação na pesquisa. Vale salientar que o projeto de pesquisa foi submetido e aprovado pelo Comitê de Ética em Pesquisa da universidade à qual as autoras estão vinculadas.

Os termos evocados a partir do TALP foram gravados, digitados no software ATLAS.TI, versão 8.0, e posteriormente submetidos à técnica da nuvem de palavras, que permitiu o cálculo da frequência das evocações e sua apresentação gráfica. Vale ressaltar que esses termos passaram por um processo de lematização, em que se procurou padronizá-los quanto a gênero, número e equivalência de conteúdo (Wachelke \& Wolter, 2011).
A partir dessa análise, os termos evocados foram agrupados em categorias e para cada categoria foi calculada sua frequência. A categorização foi feita de acordo com adjetivos que traduzem o modo como o não indígena compreende e define o indígena, o que reflete a forma como se relaciona com ele.

As entrevistas foram gravadas, transcritas e posteriormente adicionadas também ao software ATLAS.TI, compondo o corpo textual de análise. Nesse processo, as entrevistas, que são definidas como documentos primários de análise, foram submetidas a uma análise preliminar. Em seguida, foram a) selecionados trechos de narrativas (quotations), b) criados os códigos (codes), c) agrupados esses códigos (codes groups) em categorias e d) elaboradas notas de análises (memos), que auxiliam na interpretação dos dados. Por fim, foi feita a extração de resultados (outputs), que possibilitou a visualização do material analisado em uma rede semântica, que consiste numa associação de códigos capaz de favorecer a interpretação dos dados a respeito de determinado fenômeno.

O ATLAS.TI é um software da categoria CAQDAS (Computer Assisted Qualitative Data Analysis Software) que tem sido cada vez mais utilizado para analisar grande quantidade de dados, contribuindo para o alcance do rigor e da cientificidade na análise de dados qualitativos. O software pode ser utilizado com diferentes tipos de abordagens teórico-metodológicas, a partir da análise de uma unidade hermenêutica, que permite fazer relações conceituais e ter uma visão do conjunto do objeto investigado (Forte, Pires, Trigo, \& Martins, 2017; Silva, Constantino, \& Premaor, 2011).

\section{Resultados e discussão}

Para se conhecer as representações sociais do "ser índio" por meio das imagens e dos significados compartilhados por não indígenas, os resultados serão apresentados em dois momentos: análise do TALP (nuvem de palavras e categorias) e análise das entrevistas. Vale salientar que o TALP funcionou como estímulo introdutório, antes da entrevista, no sentido de suscitar o pensamento do entrevistado acerca do ser índio.

\section{Análise do TALP}

Em relação ao TALP, foram evocadas 190 palavras, na medida em que cada um dos 38 participantes evocou cinco palavras. Na Figura 1, está disposta a nuvem de palavras criada a partir do ATLAS.TI, com o objetivo de apresentar uma ilustração dos termos evocados. 


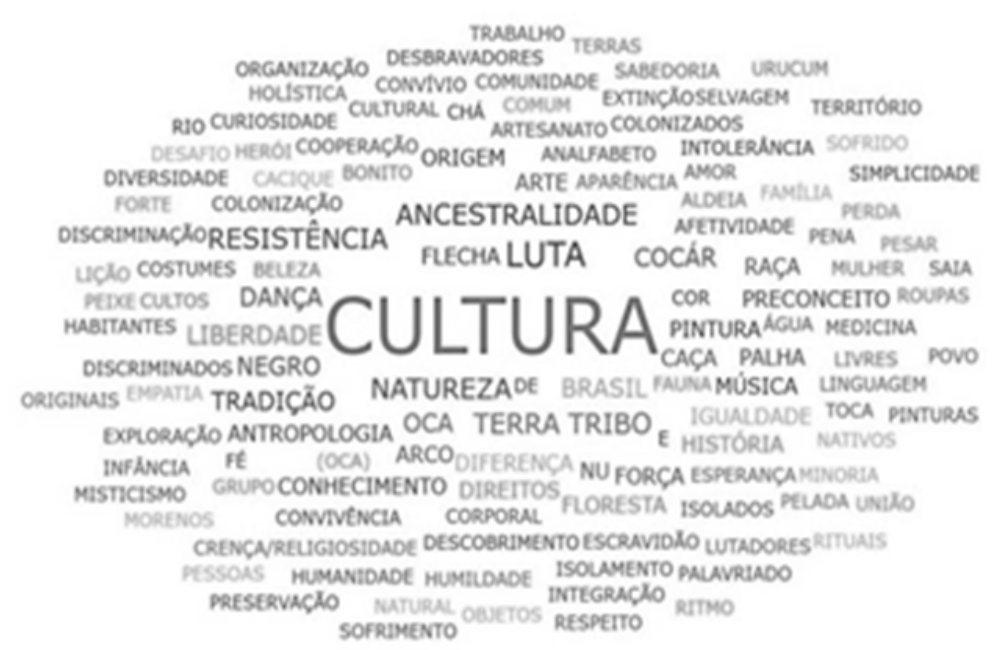

Figura 1

Nuvem de palavras evocadas no TALP.

A Figura 1 permite perceber que a palavra "cultura" se destaca como a mais evocada, o que denota um aspecto marcante na diferenciação entre indígenas e não indígenas. Na perspectiva dos estudos culturais, é na diferença que se fortalece a identidade constituída de modo relacional; e a diferença é estabelecida a partir dos aspectos simbólicos (Silva, Hall, \& Woodward, 2000). Em segundo plano, destacam-se as palavras "ancestralidade", "natureza", "terra" e "tribo", que demonstram uma representação do indígena como ser primitivo e natural. Palavras como "luta" e "resistência" remetem à imagem do indígena como ser que luta por sua existência e reconhecimento, pela preservação de sua cultura e pela garantia de direitos, elementos que colocam o indígena numa condição de sujeito de direitos (Munduruku, 2010; Potiguara, 2018).

Considerando seus significados, as palavras evocadas foram organizadas em 5 categorias: a) sujeito distinto, b) sujeito primitivo, c) sujeito de direitos, d) sujeito excluído e, por fim, e) sujeito valorizado. Destaca-se que as categorias emergiram da leitura dos termos evocados pelos participantes, com referência em estudos anteriores sobre o tema (Braga \& Campos, 2012; Lima \& Almeida, 2010; Lima et al., 2016; Luciano, 2006; Stock \& Fonseca, 2013). A Figura 2 reúne as categorias construídas a partir das evocações do TALP, acompanhadas da frequência e da porcentagem de evocação.

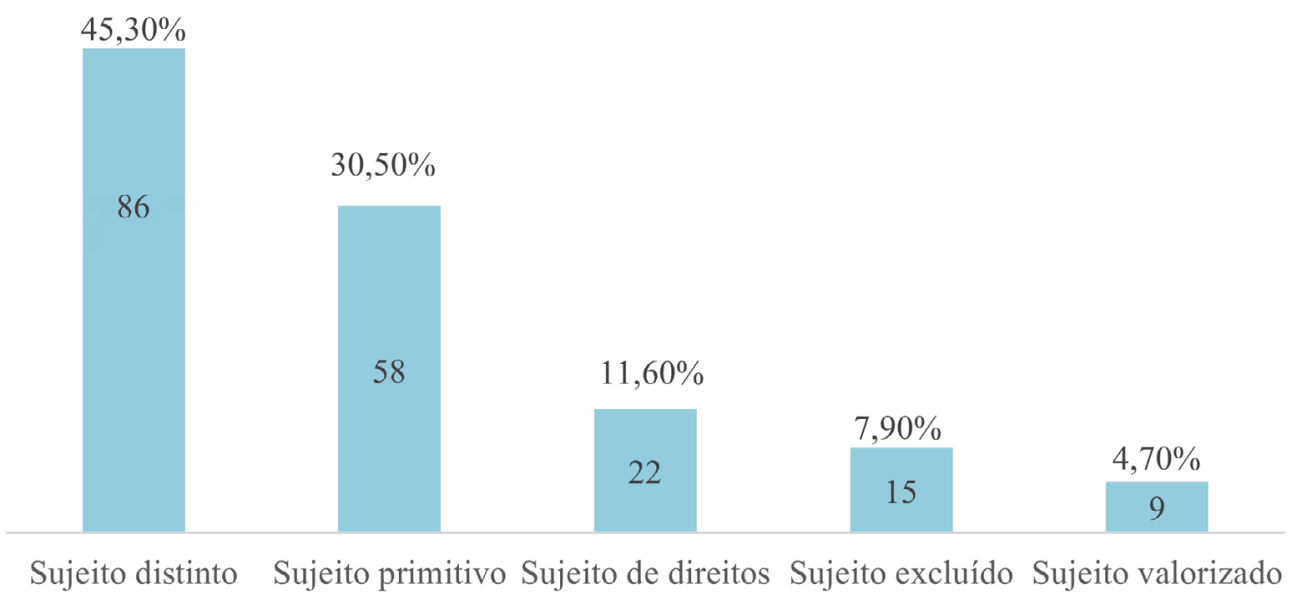

Figura 2

Frequências, porcentagens e categorias do TALP para o termo "índio". 
Como pode ser observado, a categoria que obteve maior frequência foi "sujeito distinto" ( $\mathrm{N}=86,45,3 \%$ ), seguida de "sujeito primitivo" ( $\mathrm{N}=58,30,5 \%)$. A categoria "sujeito de direitos" representou $11,60 \%$ das evocações ( $\mathrm{N}=22)$. A categoria "sujeito excluído" representou $7,90 \%$ das evocações ( $\mathrm{N}=15)$ e a categoria "sujeito valorizado" representou 4,70\% (N=9) das evocações.

"Sujeito distinto" foi a categoria com maior número de evocações referentes aos aspectos que diferenciam o indígena do não indígena. As palavras evocadas configuram as manifestações culturais como elemento marcante da caracterização e diferenciação do índio. Nessa categoria, destacam-se as seguintes evocações: cultura $(\mathrm{N}=22)$, negro $(\mathrm{N}=5)$, grupo $(\mathrm{N}=4)$, dança $(\mathrm{N}=3)$, diversidade $(\mathrm{N}=3)$, tradição $(\mathrm{N}=3)$ e rituais $(\mathrm{N}=3)$. A segunda categoria com maior número de evocações foi "sujeito primitivo", que reuniu representações que atribuem ao indígena uma condição primitiva, como ser da natureza, nitidamente ancorada na história da colonização do Brasil. As evocações mais frequentes referentes a essa categoria foram: ancestralidade $(\mathrm{N}=6)$, colonização $(\mathrm{N}=7)$, natureza $(\mathrm{N}=4)$, nativos $(\mathrm{N}=4)$, oca $(\mathrm{N}=3)$, caça $(\mathrm{N}=2)$, força $(\mathrm{N}=2)$, isolados $(\mathrm{N}=2)$ e $\mathrm{nu}(\mathrm{N}=3)$. Ambas as categorias distanciam indígena e não indígena, já que destacam aspectos que reforçam os estereótipos. Além disso, a identidade étnica dos povos indígenas, de modo geral, é compreendida como algo cristalizado e não dinâmico, que permite sofrer mudanças sem perder sua essência étnica (Barth, 1998).

A categoria "sujeito de direito" traduz o reconhecimento da condição de cidadania do indígena em relação à sociedade brasileira. As evocações que se destacaram foram: luta $(\mathrm{N}=6)$, terra $(\mathrm{N}=4)$, resistência $(\mathrm{N}=3)$, direitos $(\mathrm{N}=2)$, desafios ( $\mathrm{N}=1)$, esperança $(\mathrm{N}=1)$ e igualdade $(\mathrm{N}=1)$, termos que enfatizam as lutas dos indígenas por seus direitos e uma organização social. Considerar o indígena enquanto sujeito de direitos é reconhecê-lo como parte da sociedade, com acesso aos direitos sociais, ao mesmo tempo respeitado em suas diferenças étnicas. A palavra "terra" surge como representação da principal bandeira de luta dos povos indígenas no Brasil. Sem território demarcado, não há condição de sobrevivência (CIMI, 2019; Krenak, 2009).

A categoria "sujeito excluído" está relacionada às vivências de preconceito e discriminação que os não indígenas atribuem à vivência do indígena, bem como situações de exclusão social a que estão submetidos, seja pela própria sociedade, seja pelo Estado. As evocações mais frequentes referentes a essa categoria foram: discriminação ( $\mathrm{N}=4)$, explorados $(\mathrm{N}=3)$, sofrimento $(\mathrm{N}=1)$ e minoria $(\mathrm{N}=1)$. As categorias "sujeito de direitos" e "sujeito excluído" são complementares e traduzem o reconhecimento do indígena como parte da sociedade, ao mesmo tempo em que se reconhece o processo de exclusão social a que está exposto (Munduruku, 2010).

A categoria "sujeito valorizado" teve a menor frequência de termos evocados e abrange características positivas atribuídas aos indígenas. As evocações mais frequentes foram: afetividade $(\mathrm{N}=2)$, beleza $(\mathrm{N}=2)$, empatia $(\mathrm{N}=1)$ e sabedoria $(\mathrm{N}=1)$. Ressalta-se que a valorização do indígena na sociedade contemporânea se dá com o respeito à diferença cultural e com a identificação de aspectos positivos de seu "jeito de ser".

Portanto, as representações a respeito do indígena incluem desde uma imagem de um ser primitivo, que "possivelmente" tenha ficado no passado, até o reconhecimento de sua diferenciação e da condição de cidadania que, de certa forma, o aproxima da população brasileira em geral. O conteúdo dessas representações deve ser analisado a partir da relação estabelecida entre os grupos envolvidos, na medida em que serve para justificar o encadeamento das relações, ao mesmo tempo em que mantém a especificidade e a identidade de cada grupo (Almeida, 2009; Doise, 2002).

A definição da identidade de um grupo se apoia na construção de estereótipos, que enfatizam as diferenças entre grupos e as semelhanças em um mesmo grupo. Para explicar a hostilidade entre grupos, o preconceito e a discriminação dirigidos a grupos específicos, Tajfel (1981) trouxe para o centro do debate os processos de categorização social. Nessa perspectiva, o sentimento e a consciência de pertencer a um grupo ou uma categoria social favorece a atribuição de qualidades positivas aos membros do próprio grupo, e negativas aos membros do outro, favorecendo, assim, a construção dos estereótipos (Tajfel, 1982).

\section{Análise das entrevistas}

Os resultados obtidos a partir da análise do corpo textual das entrevistas permitiram a elaboração de uma rede semântica constituída de categorias e códigos, a fim de se compreender o fenômeno das representações sociais do indígena compartilhadas por não indígenas. A rede semântica reúne três categorias principais: a) concepção acerca do indígena; b) origem do conhecimento; e c) relação indígena versus não indígena. Elas se subdividem em 11 conjuntos de códigos. A Figura 3, a seguir, apresenta a rede semântica com as categorias e os códigos que a constituem. 


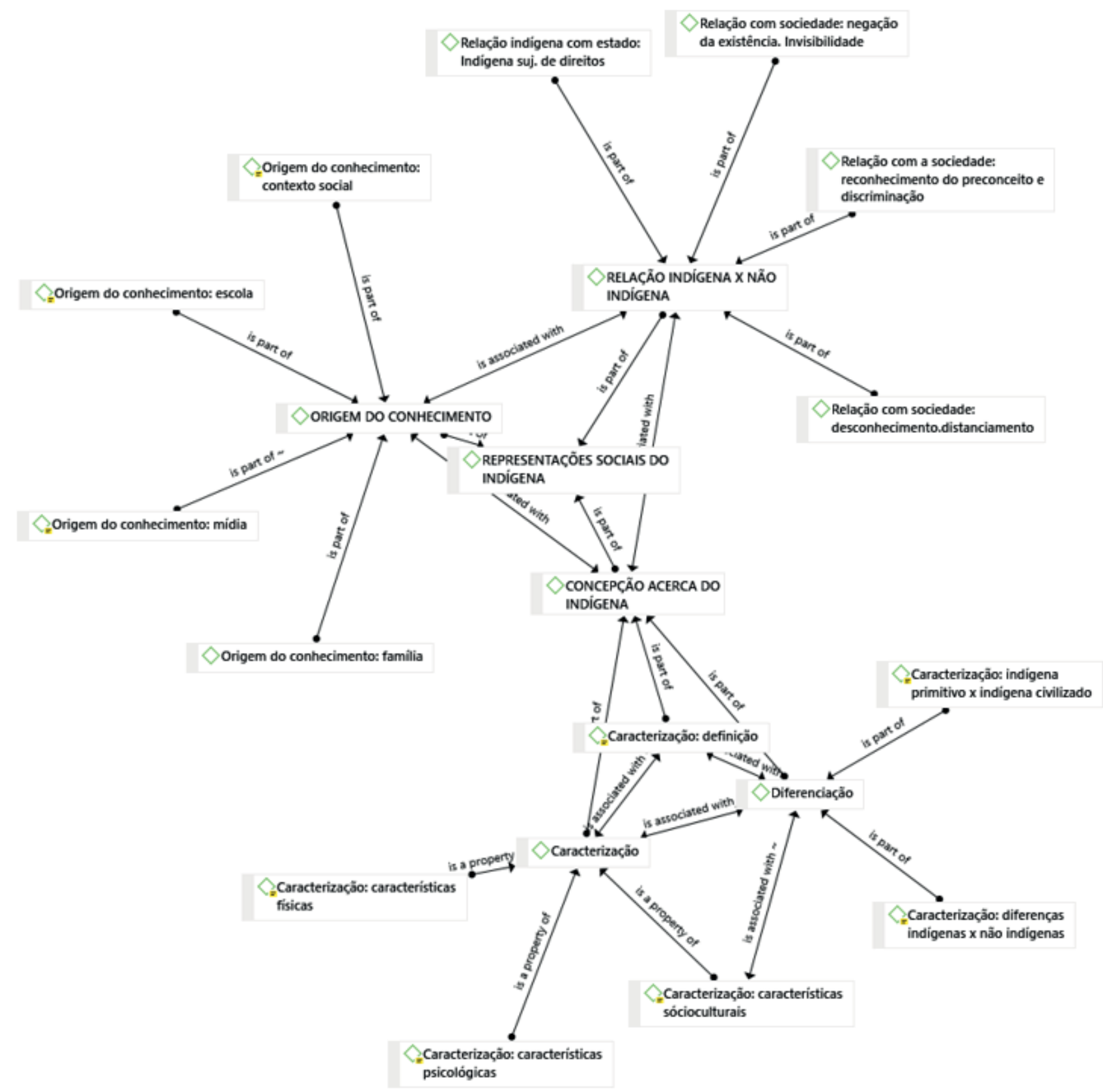

Figura 3

Rede semântica da representação social acerca do indígena.

A primeira categoria, "Concepção acerca do indígena", concentrou 288 trechos de narrativas e foi subdividida em três conjuntos de códigos: a) caracterização do indígena, que dispõe dos seguintes códigos e frequências: característica física (20), característica psicológica (13) e característica sociocultural (92), totalizando 125 trechos de narrativas; b) definição de indígena (54); e c) diferenciação, que se divide nos seguintes códigos: diferenças entre indígenas e não indígenas (71) e diferenças entre indígena primitivo e civilizado (38), totalizando 109 trechos de narrativas.

Nessa categoria, foi possível entender que as representações acerca do indígena são permeadas por aspectos que transitam desde a caracterização física, ligada a estereótipos compartilhados no imaginário dos não indígenas, passando por aspectos psicológicos, em que emergem elementos do comportamento - o "jeito de ser" do indígena -, 
até o elemento mais evidente para o não indígena: a diferenciação sociocultural, em que se apresentam aspectos próprios da cultura indígena, que marcam a diferença entre esse grupo étnico e a sociedade em geral. As citações a seguir ilustram essa discussão: "Identificamos o índio pelos traços, como cabelo liso, olhos puxados, pele morena e boca grande" (caracterização física); "Falam pouco, observam muito", "É uma pessoa sábia, paciente, tranquila. Talvez não tão sociável quanto o homem branco, mas é sábio" (caracterização psicológica); "Eles cultuam os seus deuses, têm religiões, ervas, não sei muito", "Creio que têm rituais, xamãs . . . algo mais natureza e espírito” e "Mantêm práticas colaborativas, como vivendo em uma grande família" (caracterização sociocultural).

A predominância das características socioculturais sobre as demais (físicas e psicológicas) pode ser justificada pelo fato de que estes aspectos favorecem a criação de uma simbologia a respeito de um grupo étnico que, a princípio, não é familiar. As representações sociais emergem também como um modo de dar um valor simbólico, compreender um objeto em particular, defini-lo e dar-lhe identidade. Na TRS, ancorar é classificar, nomear alguma coisa (Moscovici, 2015). Dessa forma, conceber e explicar o que é "ser indígena", a partir de elementos da cultura, facilita a compreensão do não indígena. Identifica-se a ancoragem em aspectos simbólicos do "índio primitivo" que tinha hábitos de sobrevivência na natureza, como um selvagem, e que cultiva até hoje hábitos e crenças culturais próprios.

Outro código evidenciado nos resultados foi o de "definição", que indica como o não indígena define o indígena. Esse aspecto é permeado de elementos de caracterização, diferenciação e, ainda, de identificação, todos utilizados pelo não indígena para compreender o indígena. As narrativas que exemplificam esses elementos são: "Índios são pessoas que moram em aldeias"; "É viver fora de uma sociedade que a gente vive"; "Eram os habitantes originais das terras brasileiras, até a chegada dos colonizadores"; "É um povo com um determinado tipo de cultura, que, por fazer parte de uma minoria, está ligado à resistência"; e "É um ser humano normal". As definições apresentadas evidenciam tanto a representação de indígena primitivo, diferente da sociedade, como de sujeito que está numa condição de minoria social.

O último código da categoria "Concepção acerca do indígena" foi a "diferenciação", que se divide em diferenciação feita entre indígena e não indígena e, ainda, entre indígena primitivo e indígena civilizado. Em ambas, o aspecto que se busca é a marcação da diferença. Em relação à diferenciação entre indígena primitivo e civilizado, a questão passa por uma compreensão de legitimidade da identidade étnica, que é questionada quando não se corresponde aos estereótipos estabelecidos nas representações sociais acerca do indígena, seja por elementos físicos, psicológicos ou socioculturais.

As respostas apresentadas indicam relações intergrupais que justificam o funcionamento das identidades coletivas e individuais. O processo de categorização social proporciona a acentuação de diferenças e semelhanças entre grupos distintos e ainda evidencia o status de superioridade em relação aos grupos de menor status, favorecendo o distanciamento entre eles e o aumento da discriminação do grupo "superior" contra o grupo "inferior" (Almeida, 2009).

A segunda categoria, "Origem do conhecimento a respeito do indígena", indica onde os participantes obtiveram o conhecimento sobre o indígena, ou seja, em que contexto se originou esse conhecimento. Os códigos, extraídos de 66 trechos de narrativas, foram os seguintes: escola (31), mídia (18), contexto social (16) e família (1). A fonte predominante de conhecimento é a escola, lugar onde se adquire conhecimento da historicização do país e, de modo específico, da história dos povos indígenas no período de colonização do Brasil. Algumas narrativas a seguir ilustram essa forma de acesso ao conhecimento: "Conheço através do que foi passado na escola"; "Conheço através de livros; na verdade, quando eu ainda estudava ... ., somente"; e "Lembro um pouco da época da escola, de uma forma bem maquiada, mas faz tanto tempo".

A mídia se apresenta como a segunda fonte de conhecimento sobre os indígenas. Notícias, reportagens e documentários são alguns exemplos de publicações que favorecem a construção de uma representação social a respeito de determinado fenômeno ou objeto. Como exemplos, tem-se: "O que eu conheço é o que a gente vê na televisão"; "Sei somente o que vi na época da escola e o que vejo nos jornais"; e "Nas reportagens dizem que foram atualizados, que não andam mais nus". As ideias a respeito do indígena que circulam na mídia ecoam nos espaços sociais e passam a ser naturalizadas, contribuindo de forma preponderante para a formação das representações 
sociais a respeito do indígena, a partir do não indígena (Braga \& Campos, 2012).

A terceira fonte de conhecimento é o contexto social, ou seja, o contato ou a experiência que o participante teve como possibilidade de modificar seu entendimento sobre o indígena e as questões que perpassam a realidade desses sujeitos. Algumas narrativas indicam esse aspecto: "Já estagiei na FUNAI, então eu lidava muito com os indígenas e eu vi praticamente todos os dias... . eu via a luta deles em relação às terras e eu comecei a estudar, a ler a legislação indigenista, e via o quão era contorcida a história"; e "Hoje fazendo antropologia, eles não são nada como a gente pensa, daquela visão do índio primitivo. E, na verdade, são civilizados". A última fonte de conhecimento que se evidenciou foi a família. A afirmação de um participante de que sua família é de origem indígena revela uma aproximação com a realidade desse agrupamento étnico, aproximação que proporciona outros conhecimentos. "Eu conheço através da história, porque eu estudei . . . ; também minha família é de origem indígena”.

Segundo Allport (1954), o contato intergrupal, compreendido como processo de interação entre membros de grupos efetivamente distintos, pode proporcionar a diminuição do preconceito, bem como melhorar as relações entre os grupos. Contudo, para que isso ocorra, o contato intergrupal precisa acontecer em situações de relativa igualdade de status entre os grupos envolvidos e de relações marcadas por cooperação e não competição, além do apoio institucional a essas relações (Allport, 1954).

A terceira categoria, "Relação entre indígena e não indígena", gerou os seguintes códigos: reconhecimento do preconceito e discriminação da sociedade (76), desconhecimento e distanciamento da sociedade (24), negação da existência/invisibilidade (4) e, por fim, reconhecimento do indígena como sujeito de direitos (17), totalizando 121 trechos de narrativas. Nessa categoria, surgiram narrativas que dão conta da forma como a sociedade e o Estado se relacionam com povos indígenas no contexto brasileiro. $\mathrm{O}$ reconhecimento do preconceito e da discriminação é predominante nas narrativas dos participantes, mesmo que não se apresente como posicionamento pessoal. Alguns trechos de narrativas explicitam esse aspecto da relação: "Tem muitas pessoas preconceituosas que consideram eles vagabundos, que não trabalham. Não são capazes de perceber os guerreiros que são!";
"Pessoas arcaicas, antigas, antiquadas, como se muitos deles não tivessem acesso à educação ou a outros fatores sociais"; "As pessoas veem os indígenas como um grupo atrasado que não deveria mais existir"; e "Alguém ignorante, não civilizado".

Outra postura em relação à população indígena é o desconhecimento e distanciamento, constatado em algumas narrativas: "Meu conhecimento é muito raso nessa questão, realmente pouquíssimo"; "Eu nunca tive contato, para ser bem sincera. Eu não sei se eles vivem bem"; e "Não sei muito bem, mas sei que eles têm forte contato com a natureza". Outra forma de relação é a negação de existência, exemplificada na seguinte narrativa: "Na verdade, acho que nem existe índio convivendo no nosso meio social". Vale ressaltar que a invisibilização e a negação da existência são formas de preconceito que, na história do Brasil, foram fortemente reproduzidas contra povos indígenas, negros e demais grupos minoritários (Lima, 2013).

Por fim, surgem narrativas que indicam a forma como o indígena se relaciona com o Estado, especificamente no reconhecimento dos participantes de que os indígenas têm os mesmos direitos que toda a sociedade e do próprio tratamento que recebem do Estado. As narrativas retratam a ideia de direitos pouco acessíveis: "Há muito preconceito, desigualdade... Muita coisa para ajeitar no nosso país. Pouca chance de ingressar numa faculdade. É quase invisível"; "Atualmente, muitos estão sofrendo a perda de sua terra"; "Embora eles tenham terras indígenas, existem violações e abusos nos territórios deles"; "Infelizmente vivem de forma precária. O governo não dá atenção a eles"; e "Eu acho que os indígenas conseguiram alguns direitos, mas ainda são muito discriminados hoje em dia". Enquanto grupos minoritários, os povos indígenas buscam a "mudança social", que se caracteriza pela distintividade positiva de seu grupo, no sentido de tentar diminuir a assimetria de poder em relação ao grupo majoritário (Vala \& Monteiro, 2013).

A rede semântica construída com as categorias e dos códigos analisados a partir do corpo textual de entrevistas permite a visualização da relação entre as três principais categorias - "Concepção acerca do indígena", "Origem do conhecimento sobre o indígena" e "Relação estabelecida entre indígena e não indígena". Esses três aspectos se complementam e justificam as representações sociais formadas a respeito do indígena na perspectiva do não indígena, na medida em que legitimam a imagem construída ancorada em ideias 
muitas vezes estereotipadas. Essas representações se objetivam na forma como se dão as relações entre os grupos sociais em questão (Lima \& Almeida, 2010).

A discriminação e consequentemente exclusão social do indígena ainda são retratadas na atualidade, ancoradas em valores e crenças preconceituosas do passado que se atualizam no presente. Isso se revela dado que o conhecimento do passado que atribui ao indígena a condição de primitivo ainda é respaldado, como sugere a fala de um participante: “ . . . ignorantes, não civilizados”. A desmistificação dos estereótipos, tão enraizados nas representações sociais até hoje construídas, é possível a partir da aproximação, do reconhecimento e do respeito à diferença. A constituição da identidade de indivíduos ou grupos depende de como eles se reconhecem e são reconhecidos e, consequentemente, determina as práticas em relação a eles, seja no sentido de garantia de direitos, de cobrança de deveres, seja no sentido do preconceito combatido (Lima \& Gonçalves Neto, 2010).

\section{Considerações Finais}

Neste trabalho, apresentou-se um estudo que objetivou conhecer as representações sociais do "ser indígena", considerando as imagens e significados compartilhados por não indígenas. Para tanto, utilizou-se a Teoria das Representações Sociais (TRS) associada a referências da antropologia, o que ampliou as possibilidades de compreensão desse fenômeno. Os resultados encontrados apontam que, no contexto de nossa sociedade atual, as representações sociais acerca do indígena estão ainda fortemente ligadas às ideias do indígena primitivo, como os primeiros habitantes do país. O elemento cultural é bastante significativo na identificação do "ser indígena", bem como a necessidade de ancorar sua definição nas diferenças marcantes entre esses grupos étnicos e a sociedade geral. Para as pessoas que já tiveram algum tipo de contato com grupos indígenas ou que têm conhecimento mais aprofundado da historicidade deles, há o reconhecimento da condição de cidadania, no sentido de direitos sociais adquiridos - o que, de certa forma, atribui-lhes uma condição de igualdade de direitos e, ao mesmo tempo, demonstra respeito à diversidade cultural.

Considerando o local em que a pesquisa foi realizada, as representações sociais do indígena no contexto do Ceará são permeadas pelo processo de aculturação ao qual essa população é submetida, que favorece uma "descaracterização" e uma absorção de elementos da "cultura do branco". Assim, os indígenas são questionados sobre a legitimidade de sua identidade, bem como sobre o registro histórico que, numa postura negacionista, afirmava que no Ceará não há índios.

Além de travarem uma luta por garantia de direitos legitimamente conquistados, os povos indígenas do Ceará têm de lutar pelo reconhecimento de sua identidade étnica frente à sociedade geral, pois o processo de afirmação de uma identidade grupal perpassa a autoafirmação e a legitimação do outro enquanto tal. $\mathrm{O}$ acesso ao conhecimento da condição do indígena permite a compreensão do lugar de minoria social ocupado por esses sujeitos, além de facilitar o respeito à diferença e a sensibilização acerca de suas lutas. A representação do indígena como "sujeito de direitos" reforça a condição de minoria social na qual encontram-se os povos indígenas no Brasil, que resistem e lutam contra a violação desses direitos (CIMI, 2019; Yamada, 2016).

Sobre as limitações da pesquisa, é possível que seu caráter local tenha sofrido interferência do contexto histórico vivido pelos grupos étnicos locais, que se configuram como índios do Nordeste, que tiveram sua identidade negada por um longo período. Nesse sentido, sugere-se estudos futuros comparativos com grupos indígenas de outras regiões do Brasil, bem como estudos que contemplem a visão dos próprios indígenas sobre as representações sociais do "ser indío".

\section{Referências}

Allport, G. W. (1954). The nature of prejudice. Addison-Wesley.

Almeida, A. M. O. (2009). Abordagem societal das representações sociais. Sociedade e Estado, 24(3), 713-737. https://doi.org/10.1590/S0102-69922009000300005

Associação para o Desenvolvimento Local Co-Produzido. (2017). Diagnóstico e estudo de linha de base: Projeto fortalecendo a autonomia político-organizativa dos povos indígenas. Adelco; Esplar. 
Barth, F. (1998). Grupos étnicos e suas fronteiras. In P. Poutignat \& J. Streiff-Febart (Orgs.), Teorias da Etnicidade seguido de Grupos étnicos e suas fronteiras, de Fredrik Barth (pp. 185-227). UNESP.

Bonin, T., Kirchof, E., \& Ripoll, D. (2018). Disputas pela representação do corpo indígena no Twitter. Revista Brasileira de Estudos da Presença, 8(2), 219-247.

Bourdieu, P. (1989). O Poder Simbólico. Bertrand.

Braga, M. A. (2005). Identidade étnica e os índios no Brasil. Métis: história e cultura, 4(7), 197-212.

Braga, C. F., \& Campos, P. H. F. (2012). Invisíveis e subalternos: as representações sociais do indígena. Psicologia \& Sociedade, 24(3), 499-506. https://doi.org/10.1590/S0102-71822012000300003

Castro, E. V. de. (2006). "No Brasil, todo mundo é índio, exceto quem não é" [Entrevista]. Povos Indígenas no Brasil. https://pib.socioambiental.org/files/file/PIB_institucional/No_Brasil_todo_mundo_\%C3\%A9_\%C3\%ADndio.pdf

Chaves, A. M., \& Silva, P. L. (2013). Representações Sociais. In L. Camino, A. R. Torres, M. E. O. Lima \& M. E. Pereira (Orgs.), Psicologia Social: temas e teorias (pp. 413-464). Technopolitik.

Conselho Indigenista Missionário. (2019). Relatório da violência contra povos indígenas no Brasil: Dados de 2018.

Deschamps, J. C., \& Moliner, P. (2009). A Identidade em Psicologia Social: Dos processos identitários às representações sociais. Vozes.

Doise,W. (2002). Da psicologia social à psicologia societal. Psicologia: Teoria e Pesquisa, 18(1), 27-35. https://doi.org/ $10.1590 /$ S0102-37722002000100004

Fernandes,F.S.,Ferraz,F.,Salvaro,G.I.J.,Castro,A.,\&Soratto,J.(2018).RepresentaçõesSociaisdosprofissionaisdesaúde sobre a terminalidade infanto-juvenil. CEFAC, 20(6), 742-752. https://doi.org/10.1590/1982-021620182062618

Forte, E. C. N., Pires, D. E. P., Trigo, S. V.V. P., \& Martins, M. M. F. (2017). A hermenêutica e o software ATLAS.TI: União promissora. Texto Contexto Enfermagem, 26(4), 1-8. https://doi.org/10.1590/0104-07072017000350017

Jaenisch, D. B. (2017). Poéticas e Políticas da Relação: apontamentos a partir da ação de Ailton Krenak na Assembléia Constituinteeseudeslocamentoparaespaçosdeartecontemporânea.Iluminuras, 18(43),215-239.https://doi.org/ $10.22456 / 1984-1191.72884$

Krenak, A. (2009). Ideias para adiar o fim do mundo. Companhia das Letras.

Leite, Y. F. (1979). A Construção da Pessoa nas sociedades indígenas. Boletim do Museu Nacional, Antropologia, n. 32. Cia. Editora Fon-fon e Seleta.

Lima, A. F., \& Gonçalves Neto, J. U. (2010). Reconhecimento Social, Identidade e Linguagem: primeiros fragmentos de uma pesquisa sobre as perspectivas teóricas atuais no contexto da Psicologia Social. Revista Psicologia e Saúde, 2(1), 90-97. https://doi.org/10.20435/pssa.v2i1.40

Lima, M. E. O. (2013). Preconceito. In L. Camino, A. R. Torres, M. E. O. Lima \& M. E. Pereira (Orgs.), Psicologia Social: temas e teorias (pp. 589-640). Technopolitik.

Lima, M. E. O., \& Almeida, A. M. M. (2010). Representações sociais construídas sobre os índios em Sergipe: ausência e invisibilidade. Paidéia, 20(45), 17-27. https://doi.org/10.1590/S0103-863X2010000100004

Lima, M. E. O., Faro, A., \& Santos, M. R. (2016). A desumanização presente nos estereótipos de índios e ciganos. Psicologia: Teoria e Pesquisa, 32(1), 219-228. https://doi.org/10.1590/0102-37722016012053219228

Luciano, G. S. (2006). O índio brasileiro: o que você precisa saber sobre os povos indígenas no Brasil de hoje. Secretaria de Educação Continuada, Alfabetização e Diversidade; LACED/Museu Nacional. http://www.educadores. diaadia.pr.gov.br/arquivos/File/pdf/indio_brasileiro.pdf

Minayo, M. C. S. (2017). Amostragem e saturação em pesquisa qualitativa: consensos e controvérsias. Pesquisa Qualitativa, 5(7), 1-12.

Moliner, P., \& Guimelli, C. (2015). Les représentations sociales: fondements historiques et développements récents. Presses Universitaires de Grenoble.

Moscovici, S. (2015). Representações Sociais: Investigações em Psicologia Social.Vozes.

Mozumder, M. K., \& Haque, S. (2015). Stereotypical Thoughts and Perceptions Among Chakma and Settler Bengalis in Southeastern Bangladesh. Peace and Conflict: Journal of Peace Psychology, 21(2), 285-288. https://doi.org/ $10.1037 /$ pac0000091

Munduruku, D. (2010). Mundurukando. Edição do Autor. 
Oliveira, J. P. (1998). Uma etnologia dos “índios misturados”? Situação colonial, territorialização e fluxos culturais. Mana, 4(1), 47-77. https://doi.org/10.1590/S0104-93131998000100003

Organização das Nações Unidas. (2007). Declaração das Nações Unidas sobre o direito dos povos indígenas. https://pib.socioambiental.org/files/file/PIB_institucional/DECLARACAO_DAS_NACOES_UNIDAS_SOBRE_ OS_DIREITOS_DOS_POVOS_INDiGENAS.pdf

Palacios-Espinosa, X., González, M. I., \& Zani, B. (2015). Las representaciones sociales del cáncer y de la quimioterapia en la familia del paciente oncológico. Avances en Psicología Latinoamericana, 33(3), 497-515. https://doi.org/ 10.12804/apl33.03.2015.09

Pinheiro, J. (2002). Ceará: Terra da Luz, terra dos índios: história, presença e perspectiva. Ministério Público Federal; Fundação Nacional do Índio; Instituto do Patrimônio Histórico e Artístico Nacional.

Potiguara, E. (2018). Metade Cara, Metade Máscara. Grumin.

Salas, M. M. (2011). Percepción de Discriminación Social em um Grupo Indígena Costarricense: Los Huetares de Quitirrisi. Actualidades en Psicología, 25(112), 137-144.

Silva, A. M., Constantino, G. D., \& Premaor, V. B. (2011). A contribuição da teoria das representações sociais para análise de um fórum de discussão virtual. Temas em Psicologia, 19(1), 233-242.

Silva, T. T. (Org.), Hall, S., \& Woodward, K. (2000). Identidade e diferença: A perspectiva dos estudos culturais. Vozes.

Souza, M. N., \& Barbosa, E. M. (2011). Direitos indígenas fundamentais e sua tutela na ordem jurídica brasileira. Âmbito Jurídico, 15(85), 20-34.

Stock, B. S., \& Fonseca, T. M. G. (2013). Para desacostumar o olhar sobre a presença indígena no urbano. Psicologia \& Sociedade, 25(2), 282-287.

Tajfel, H. (1981). Human groups and social categories. Cambridge University Press.

Tajfel, H. (1982). Social Psychology of Intergroup Relations. Annual Review of Psychology, 33, 1-39. https://doi.org/ 10.1146/annurev.ps.33.020182.000245

Vala, J., \& Castro, P. (2013). Pensamento social e representações sociais. In J.Vala \& M. B. Monteiro (Orgs.), Psicologia social (pp. 38-52). Calouste Gulbenkian.

Vala, J., \& Monteiro, M. B. (2013). Psicologia Social. Calouste Gulbenkian.

Valentim, J. P. (2013). Que futuro para representações sociais? Psicologiae Saber Social, 2(2), 158-166. https://doi.org/ 10.12957/psi.saber.soc.2013.8790

Wachelke, J. F. R., \&Wolter, R. P. (2011). Critérios de construção e relato da análise prototípica para representações sociais. Psicologia: Teoria e Pesquisa, 27(4), 521-526. https://doi.org/10.1590/S0102-37722011000400017

Yamada, É. (2016).Povos indígenas e os direitos humanos. PovosIndígenas no Brasil.https://pib.socioambiental.org/ pt/Povos_ind\%C3\%ADgenas_e_os_direitos_humanos

\section{Sílvia Barbosa Correia}

Doutora em Psicologia pelo Programa de Pós-graduação em Psicologia da Universidade de Fortaleza (UNIFOR), Fortaleza - CE. Brasil.

E-mail: silviapsi.barbosa@gmail.com

(1) https://orcid.org/0000-0001-8604-0166

\section{Luciana Maria Maia}

Professora Dra. do Programa de Pós-graduação em Psicologia da Universidade de Fortaleza (UNIFOR), Fortaleza - CE. Brasil.

E-mail: lumariamaia@hotmail.com

(1) http://orcid.org/0000-0003-1491-5685 
Endereço para envio de correspondência:

Universidade de Fortaleza. Avenida Washington Soares, 1321, Bloco E, Sala 13. CEP: 60811-905. Fortaleza - CE. Brasil.

Recebido 17/03/2019

Aceito 03/09/2020

Received 03/17/2019

Approved 09/03/2020

Recibido 17/03/2019

Aceptado 03/09/2020

Como citar: Correia, S. B., \& Maia, L. M. (2021). Representações Sociais do “Ser Indígena”: Uma Análise a Partir do não Indígena. Psicologia: Ciência e Profissão, 41, 1-15. https://doi.org/10.1590/1982-3703003221380

How to cite: Correia, S. B., \& Maia, L. M. (2021). Social Representations of "Being Indigenous": an Analysis from the Non-indigenous. Psicologia: Ciência e Profissão, 41, 1-15. https://doi.org/10.1590/1982-3703003221380

Cómo citar: Correia, S. B., \& Maia, L. M. (2021). Representaciones Sociales de “Ser Indígena”: un Análisis de los no Indígenas. Psicologia: Ciência e Profissão, 41, 1-15. https://doi.org/10.1590/1982-3703003221380 